\title{
Instagram como recurso didáctico para desarrollar la escritura creativa: caso microrrelato
}

\section{Instagram as a teaching resource to develop creative writing: micro story case}

Recibido: 9 de octubre de 2019 | Aprobado: 25 de noviembre de 2019

\section{Resumen}

La lectura y la escritura representan dos de las competencias más significativas para el desarrollo humano. Las capacidades comunicativas de las personas dependen, en gran medida, de estas actividades. En este sentido, las redes sociales de internet ofrecen grandes oportunidades a los profesionales de la educación, especialmente a los profesores de Lengua y Literatura, para desarrollar secuencias de enseñanza-aprendizaje. Consciente de esta realidad, en este artículo se proponen un conjunto de actividades que promueven la escritura creativa. En sentido general, el objetivo de este texto es ofrecer una propuesta didáctica que promueve la utilización de la red social Instagram como recurso didáctico para el desarrollo de competencias de escritura creativa de microrrelatos. Se concluye que los maestros deben promover la implementación de estos recursos en sus prácticas pedagógicas y así superar en parte las barreras espaciotemporales y generacionales. La red social Instagram puede funcionar como un recurso didáctico a partir de la planificación adecuada de actividades pedagógicas que incluyan su utilización.

Palabras clave: redes sociales; Instagram; microrrelato; secuencias didácticas; escritura creativa.

\section{Abstract}

Reading and writing represent two of the most significant skills for human development. The communicative capacities of people depend, to a large extent, on these activities. In this sense, social networks on the Internet offer great opportunities for education professionals, especially teachers of Language and Literature, to develop teaching-learning sequences. Aware of this reality, this article proposes a set of activities that promote creative writing. In general, the objective of this text is to offer a didactic proposal that promotes the use of the social network Instagram as a didactic resource for the development of creative writing competencies of micro stories. It is concluded that teachers should promote the implementation of these resources in their pedagogical practices and thus partially overcome the spatio-temporal and generational barriers. The Instagram social network can function as a didactic resource based on the proper planning of pedagogical activities that include its use.

Keywords: social networks, Instagram, short story, teaching sequences, creative writing.

\footnotetext{
* Profesor titular de la Escuela de Letras de la Universidad Autónoma de Santo Domingo, imparte Letras Básicas y Morfología y Sintaxis. Para contactar al autor: faustinomedina2683@gmail.com
}

ISSN (en línea): 1814-4152 / Sitio web: http://cuaderno.pucmm.edu.do

Cómo CITAR: Medina, F. (2020). Instagram como recurso didáctico para desarrollar la escritura creativa: caso microrrelato. Cuaderno de Pedagogía Universitaria, Vol. 17, n. ${ }^{\circ}$ 33, enero-junio, pp. 84-93 


\section{Introducción}

La lectura y la escritura son dos de las competencias más importantes para el desarrollo de cualquier ser humano. Estas inciden de manera directa en el perfeccionamiento de las capacidades comunicativas de las personas. Por eso, las instituciones formativas se preocupan de que cada estudiante adquiera, a lo largo de su escolaridad, esta competencia. Sin ella, las interacciones lingüísticas serían muy limitadas. Esto se debe a que de esta competencia depende, en gran medida, el uso adecuado de la lengua por parte de los sujetos que conforman los grupos sociales.

Tomando en cuenta lo antes planteado, la academia se ha ocupado de incluir el desarrollo de las competencias genéricas en el diseño de los programas de todas las carreras, con el fin de favorecer el dominio de la lectura y la escritura, entre otras competencias. Esta iniciativa de las universidades parte de la necesidad de lograr profesionales más competentes, capaces de dominar los textos de su carrera y con un alto nivel cultural para que puedan formar parte activa de una comunidad discursiva. A este proceso de desarrollo de las competencias comunicativas se le ha denominado alfabetización académica.

La alfabetización académica representa un "proceso de enseñanza que favorece el acceso de los estudiantes a las diferentes culturas escritas de las disciplinas" (Carlino, 2005, p.17). Para lograr una alfabetización efectiva el docente de cualquier disciplina debe tomar en cuenta "la influencia del contexto social, cultural y político sobre la manera que las personas usan y adquieren los conceptos básicos de cálculo numérico, lectura y escritura" (Unesco, 2008, p.17).

Según las ideas antes planteadas, el proceso de alfabetización académica es responsabilidad de todos los docentes sin importar si son o no del área de Lengua y Literatura. Por lo tanto, los profesores de otras asignaturas deben incluir estrategias que desarrollen las competencias lingüísticas. A pesar de estos esfuerzos conjuntos entre las instituciones y sus docentes, diferentes investigaciones demuestran que los estudiantes presentan serias dificultades para afrontar las tareas de lectura y escritura propuestas en la universidad (Piacente y
Tittarelli, 2006; García y Álvarez, 2009, 2010).

Esta situación puede ser producto de varios factores. Entre ellos, destacan: la poca cultura lectora y escritural de los estudiantes; la escasa atención a estos dos aspectos en la formación preuniversitaria y la utilización desmedida y desorientada de recursos tecnológicos como la internet y las redes sociales. En ese mismo orden, Canales (2014) añade que factores como la pobreza extrema, marginalidad, analfabetismo de los padres también pueden afectar seriamente la capacidad de los alumnos para desarrollar estas tareas.

Por su parte, Olave Arias, Cisneros Estupiñán y Rojas García (2013) plantean que las tres dificultades que más afectan el aprendizaje de la lectura y escritura en la universidad son: en primer lugar, los hábitos lectores de los alumnos; segundo, las diferencias conceptuales entre docentes y estudiantes con relación a los términos lectura y escritura y a sus procesos y, en tercer lugar, la evaluación de las producciones por parte de los docentes.

A todo esto, se agrega la desmotivación de muchos alumnos para realizar las actividades propuestas por sus maestros. Esto pudiera ocurrir, en muchos de los casos, porque dichos ejercicios no son o no resultan interesantes. El tradicionalismo de muchos docentes provoca que algunos estudiantes no se motiven a realizar las actividades que estos formulan. Según Pérez Sánchez y Pérez Morán (2019), los docentes no deberían "utilizar el mismo medio y las mismas prácticas tradicionales ya que, los alumnos aprenden y adquieren competencias de manera diferente, además de que el uso de las nuevas tecnologías brinda una gran diversidad de materiales" (p.7).

Los estudiantes de hoy "son sujetos que se encuentran interactuando cada día, dentro y fuera del aula, con hipertextos, hipermedias, multimedias, que han sido producidos por otros con diferentes fines educativos, lúdicos, recreativos" (Calle, 2018, p.341). A partir de esta afirmación, se puede deducir que el profesor necesita incorporar estos formatos comunicativos en sus prácticas. Además, debe aprovechar plataformas digitales como Twitter, Facebook e Instagram para desarrollar actividades de lectura y escritura. Con ello podría lograr la integración de muchos de sus estudiantes, debido 
a que algunos de estos prefieren interactuar en los entornos que ofrecen estas tecnologías. En ese sentido, Blasco, Lorenzo y Sarsa (2018) consideran que en los procesos de enseñanza-aprendizaje desarrollados en las redes sociales los estudiantes se muestran más motivados, comprometidos y autónomos.

Este artículo tiene como objetivo general ofrecer una propuesta que promueve la utilización de la red social Instagram como recurso didáctico para el desarrollo de competencias de escritura creativa de microrrelatos. Como objetivos específicos pretende:

a. Identificar los tipos, funciones y características de los recursos y medios didácticos.

b. Caracterizar los microrrelatos como parte de los géneros narrativos de mayor auge en la actualidad.

c. Motivar el uso de la red social Instagram como recurso didáctico para incentivar la producción y difusión de microrrelatos.

Para el logro de estos objetivos en lo adelante se plantean y discuten los fundamentos teóricos que sustentan este estudio. Se desarrollan los subtítulos: recursos didácticos: definición, tipos y criterios para su selección; Instagram como recurso didáctico; el microrrelato en los entornos digitales; metodología, propuesta didáctica y conclusión.

Recursos didácticos: definición, tipos y criterios para su selección

El desarrollo de buenas prácticas, regularmente, requiere la utilización de recursos didácticos pertinentes. Para Sierras (2002), los recursos didácticos son "todos aquellos instrumentos que, por una parte, ayudan a los formadores en su tarea de enseñar y, por otra, facilitan a los alumnos el logro de los objetivos de aprendizaje" (p.19). Por su parte, Castillo y Cabrerizo (2006) afirman que, "en un sentido amplio, cualquier elemento que se utilice al servicio del proceso instructivo, puede ser considerado como medio, recurso o material didáctico" (p.258). Es importante destacar que, como se explica antes, cualquier elemento, aunque no sea tecnológico puede emplearse como recurso en un salón de clase. Todo dependerá de si su utilización favorece el aprendizaje de los alumnos.
Los recursos didácticos, más que simples instrumentos pedagógicos, son mediadores entre los profesores y el proceso de aprendizaje. Estos permiten el logro de los objetivos educativos del docente. "Esta función mediadora general se desglosa en diversas funciones específicas que pueden cumplir los recursos en el proceso formativo: estructuradora de la realidad, motivadora, controladora de los contenidos de aprendizaje, innovadora, etc." (Blanco Sánchez, 2012, p.6). Por lo tanto, las propuestas didácticas novedosas toman muy en cuenta los recursos didácticos porque estos facilitan las tareas del profesorado y fomentan el desarrollo de competencias en los estudiantes.

Castillo y Cabrerizo (2006) plantean diferencias importantes entre los medios didácticos y los recursos educativos. Los primeros son materiales diseñados para facilitar los procesos de enseñanzaaprendizaje; los segundos, son elementos que, aunque no fueron elaborados con fines educativos, en un contexto determinado podrían ser empleados por los docentes en sus prácticas. A partir de esta diferenciación, se puede afirmar que un libro de texto de Ciencias Naturales es un medio didáctico y que una película es un recurso educativo susceptible para ser utilizado en cualquier asignatura.

La clasificación de los medios didácticos y de los recursos educativos depende de la plataforma que los soporta. Castillo y Cabrerizo (2006) han estructurado la siguiente clasificación:

\section{Materiales convencionales: a)} impresos: libros, fotocopias, periódicos, documentos... b) tableros didácticos: pizarra, franelograma... c) materiales manipulativos: recortables, cartulinas... d) juegos: arquitecturas, juegos de sobremesa... e) materiales de laboratorio;

2. Materiales audiovisuales: a) imágenes fijas proyectables: diapositivas, filminas, fotografías... b) materiales sonoros: cintas, discos, programas de radio... c) materiales audiovisuales: montajes audiovisuales, películas, videos, programas de televisión;

3. Nuevas tecnologías: a) programas informáticos: CDs, DVDs... b) servicios telemáticos: páginas web, correo 
electrónico, chats, foros... c) TV y video interactivo. (p.261)

A pesar de la gran variedad de recursos didácticos, los profesores presentan indecisión a la hora de seleccionarlos. Esto se debe a que la eficacia de un material didáctico no depende de la calidad o modernidad de este, sino de otros criterios. Castillo y Cabrerizo (2006) consideran que la selección de un buen material depende de los siguientes aspectos curriculares:

1. Los objetivos: el profesor debe analizar qué recurso didáctico es el más idóneo para el logro de sus fines educativos.

2. Los contenidos: el recurso elegido debe favorecer el desarrollo de los temas que propone el programa de la asignatura para el logro de las competencias que los alumnos necesitan.

3. Los estudiantes: se deben considerar las características de estos y sus posibilidades para utilizar un recurso didáctico determinado. El maestro debe conocer sus estilos de aprendizaje, saberes previos, experiencias, motivaciones, entre otros aspectos.

4. El contexto: no todos los medios didácticos son aplicables en todos los lugares y momentos. Es importante tomar en cuenta si el contexto favorece o no la utilización de un recurso.

5. Las estrategias didácticas: por más novedoso o moderno que sea un recurso no será útil si las estrategias del profesor no lo ameritan.

\section{Instagram como recurso didáctico}

Las redes sociales de Internet se han convertido en una de las herramientas más utilizadas por las personas. Casi todos los estamentos de la sociedad utilizan estos entornos digitales para llevar a cabo sus actividades. "Vivimos en un mundo conectado, la red de redes, Internet, forma parte de nuestra idiosincrasia, es un elemento clave en nuestro día a día" (Marín Díaz, Cabero Almenara, 2019, p.26). En tal sentido, el desarrollo de proyectos de lectura y escritura en estos espacios representa una innovación pedagógica que puede fomentar la creatividad y motivación para lograr estas competencias comunicativas.

La utilización de las TIC en el ámbito académico, además, tiene como propósito principal potencializar el tiempo de los estudiantes fuera y dentro del salón de clases. Se trata de un diseño metodológico que prioriza el desplazamiento de las actividades de aprendizaje a los espacios habituales de los alumnos. Este desplazamiento se realiza mediante herramientas como YouTube, Vimeo, Slideshare, Scribd, Facebook, Twitter, Instagram, entre otros entornos o plataformas digitales.

Para los fines de esta investigación, se tomará a Instagram como plataforma digital con posibilidades de convertirse en herramienta educativa. Esta aplicación nació el 6 de octubre de 2010. Su finalidad fue facilitar la creación, edición y publicación de fotografías por medio de teléfonos inteligentes. Según Cantón Correa y Pascual (2018), Instagram inició como una especie de "twitter con imágenes", "pero probablemente fue la posibilidad de usar diferentes filtros rápidos (muchos de ellos de tipo vintage) a sus imágenes lo que hiciera que su crecimiento fuera algo nunca visto en el mundo de las redes sociales digitales" (p.235).

Esta red social es muy utilizada por los jóvenes universitarios. Jurado, Woelfert, Giovagnola, Faisal y Peralta (2018) afirman que todos los alumnos que participaron en su proyecto, La incorporación de la red social Instagram con fines didácticos en el Curso de Microscopía Electrónica de la FCVUNLP, tenían acceso a la tecnología digital por medio de sus aparatos electrónicos (celulares, tabletas y computadoras). "Todos manifestaron conocer distintas redes sociales(Twitter, Facebook, Instagram) y la mayoría aseguró tener una cuenta en la red social Instagram" (p.64). La popularidad de Instagram entre los jóvenes universitarios la convierte en un recurso que puede y debe ser aprovechada por la academia. Esta plataforma posibilita la elaboración e implementación de proyectos educativos desde cualquier área de formación. 
La utilización de discursos gráficos y audiovisuales hace que esta red social sea idónea para desarrollar las competencias comunicativas. Una de las habilidades de la comunicación que se puede trabajar en Instagram es la escritura, sobre todo, la escritura creativa. Como la inmediatez y la brevedad son dos de las características principales de la comunicación en los entornos virtuales, se ha considerado que la redacción de microrrelatos en esta red social puede resultar una propuesta didáctica idónea y factible.

\section{La escritura creativa y sus beneficios}

La escritura es una de las formas de manifestación de la lengua. Su dominio depende de la lectura y de prácticas constantes. De este modo, si una persona desea escribir artículos científicos o ensayos argumentativos debe leer y escribir con persistencia discursos de estos tipos. Lo mismo sucede con la escritura creativa. Esta se puede definir como la escritura que se realiza mediante la utilización de ejercicios que estimulan la creatividad. A través de esta escritura, la palabra puede transformar la realidad en ficción. En ese mismo tenor, Cancino Peña, Fontecha Barbosa, Ramírez Amado y Parra Arias (2019) sostienen que "la palabra es creación también es acción, porque el que escribe se enfrenta a la construcción artística y contemplativa del mundo" (p.96).

La utilización de técnicas de escritura creativa puede favorecer la producción de textos de diversos géneros: artículos de opinión, ensayos, novelas, poemas, cuentos, microrrelatos, entre otros. Son muchos los beneficios que ofrece este tipo de escritura: favorece la imaginación, mejora la concentración, desarrolla el lenguaje, la expresión, relaja y entretiene, entre otros. Además, "incentiva al estudiante a crear, pensar y trasmitir sus sentimientos plasmándolos de manera escrita" (Mendieta Sierra, 2018, p.28).

Por su parte, Páez (2007) propone algunos ejercicios de escritura creativa. Entre ellos están: a) escribir a partir de un final: consiste en tomar el final de un cuento clásico y recrear una historia desde ese punto: b) el binomio fantástico: se trata de tomar dos palabras que no tengan ninguna relación y, con ellas como base, construir un texto; c) el monólogo interior: es la presentación de pensamientos caóticos y dispersos de un personaje; d) el plagio creativo: se toma un texto literario clásico y se transforma en uno nuevo, pero contando la misma historia o utilizando los mismos personajes; e) el diario íntimo: este consiste en la escritura día a día de un diario, registrando hechos reales o ficticios.

\section{El microrrelato en los entornos digitales}

La literatura es una de las principales herramientas para la manifestación de las realidades humanas. En la época clásica, esta se dividía en tres grandes géneros: poético-lírico, épico-narrativo y dramático (Romero Valdés, H., Ojeda Ramírez y Díaz González, 2018). En la actualidad se consideran otros géneros como la novela, el cuento y los microrrelatos. Este último ha sido nombrado de diversas formas: "relatomínimo, hiperbreve, ultracorto, microscópico, cuántico, bonsái, jíbaro, liliputiense, microcuento, minirrelato, minicuento, brevicuento, descuento, nanocuento, textículo" (Hernández, 2016, p.69). Sin embargo, a pesar de todas estas opciones, parece haber conceso en la utilización del nombre microrrelato para denominar este tipo de textos.

Un microrrelato es una narración muy breve que se apoya en el conocimiento del mundo de los lectores para construir una historia. Liu (2019) plantea que "el microrrelato es un género de moda en España, bautizado como el cuarto género narrativo" (p.154). Por otro lado, Árdenas Ruiz (2018) considera que este tipo de texto "se construye a partir de hechos inéditos que hayan causado perplejidad en el sujeto que narra". Como se observa, un microrrelato requiere la utilización de palabras adecuadas y precisas, es decir, términos que sean capaces de representar, de manera directa, los hechos que se intentan contar.

Por su parte, Martínez (2011) sostiene que un microrrelato exige a los lectores mayor concentración cognitiva, "ya que la corta extensión, sumada a la concentración de recursos, provoca durante la lectura actitudes, elaboraciones mentales y reacciones diferentes de aquellas que se experimentan" (p.62). Como explica este autor, a pesar de su brevedad, el microrrelato exige mayor atención de sus lectores. Esto se debe a que cada elemento lingüístico y literario debe desempeñar una función significativa. 
Aparte de la brevedad, otras características importantes del microrrelato son la utilización de referencias históricas, los finales abruptos y la participación de los lectores en la construcción de la historia contada (Larrea, 2004, 2019). Con respecto a la primera característica, es un recurso que se emplea en muchos cuentos de este tipo. Como la parte lingüística es regularmente breve, se recurre a relacionar el cuento con algún hecho, personaje o historia de ficción. Los finales abruptos se deben a que en los microrrelatos predomina, por un lado, la no conclusión de la historia; y, por otro, los finales abiertos. Todo esto permite la tercera característica, la participación de los lectores en la construcción de la obra. Estos, casi siempre, conocen o investigan la referencia histórica que se les presenta en el cuento y por ello pueden aportarle un final.

Estas características y la composición del microrrelato favorecen que este género narrativo se produzca y se difunda en las redes sociales. Alonso (2019) reitera el uso creciente de este espacio virtual para el florecimiento de este género y dice que: "un fenómeno destacado por la crítica es la expansión de los microrrelatos en internet" (p.94). Esto se debe a cualidades como el fragmentarismo y la intertextualidad, debido a que estas hacen que este tipo de texto se adapte a los contextos virtuales.

Como se ha apuntado más arriba, los escritores siempre han encontrado los medios para llevar hasta los demás sus ideas, pues la literatura es y seguirá siendo uno de los canales principales para expresar la vida y sus circunstancias. A la par, la internet se ha erigido como un potente medio para la difusión de los hechos sociales que las personas consideran relevantes. En tal sentido, esta herramienta puede y debe ser utilizada para la difusión literaria. Draus (2019) plantea que "la red permite, e incluso exige, el traslado de las acciones del artista de la esfera local a la esfera global sea en la etapa de producción o de recepción" (p.68). Por lo tanto, los docentes y los estudiantes deben aprovechar la internet y las redes sociales para difundir sus ideas.

\section{Propuesta didáctica}

Esta propuesta didáctica consiste en la utilización de espacios virtuales como Instagram para el desarrollo y promoción de la escritura de microrrelatos, por lo que su aplicación puede favorecer la comprensión y producción de este tipo de textos en los estudiantes. Tomando todo lo anterior en cuenta, este estudio propone el desarrollo de la estrategia en seis pasos. A seguidas se explica cada uno de ellos:

- 1er paso: consiste en la creación de un perfil privado en la red social Instagram. El profesor debe establecer el perfil y agregar contenido relacionado al tema en cuestión. Se necesita que este espacio cuente con microrrelatos de autores reconocidos. Después, el docente debe motivar a sus estudiantes para que soliciten su aceptación en el espacio creado.

- 2do paso: se indicará la lectura de algunos de los microrrelatos colgados en la página de Instagram. Luego, se publicará una imagen con las preguntas: Según los modelos que has analizado, ¿cómo definirías el concepto microrrelato? y ¿cuáles son sus principales características? Cada estudiante comentará la publicación respondiendo las interrogantes planteadas. Finalmente, el docente colgará definiciones y características del término según varios autores y compartirá varios artículos sobre los microrrelatos. Estos serán leídos fuera del aula y discutidos en el aula.

- 3er paso: consiste en la producción de un microrrelato. Los estudiantes escogerán una de dos posibilidades: podrán crear un texto utilizando el plagio creativo o empleando el binomio fantástico. Para Páez (2007), estas dos técnicas narrativas pueden potencializar la creatividad de las personas. La primera consiste en tomar una historia tradicional como Caperucita Roja y contarla desde otro punto de vista, por ejemplo, la del lobo o la del leñador; la segunda se basa en el uso de dos palabras, sin relación semántica, en un mismo texto. Para este proyecto se propone la utilización del microrrelato El suicida de Enrique Anderson Imbert. La idea es utilizar el plagio creativo para crear un microrrelato donde se narre la historia del texto de 
referencia, pero desde otra perspectiva. Con respecto al binomio fantástico, se sugiere la utilización de los vocablos lluvia y teléfono. Los estudiantes deberán imaginar una situación y contarla empleando estas palabras.

- 4to paso: una vez creado el texto, deberán revisarlo por medio de una rúbrica facilitada por el maestro (ver anexo). Primero, corregirán su producción de manera individual; segundo, volverán, en equipos de tres personas, a revisarla.

- 5to paso: terminado el proceso de revisión, las producciones serán publicadas como escenas de Stories o Historias de Instagram. Deberán dividir su microrrelato en tres escenas o partes y publicarlas en este formato. Pueden utilizar imágenes para complementar el texto o los fondos que facilita la misma aplicación. Finalmente, el profesor evaluará las producciones y, por medio de mensajes privados o directos, ofrecerá su valoración a cada alumno.

- 6to paso: se solicitará al grupo su participación en una encuesta digital con el fin de medir la aceptación o nivel de satisfacción con respecto a esta experiencia formativa.

\section{A modo de conclusión}

Definitivamente, las redes sociales de internet se han convertido en espacios o puntos de reunión. Estas plataformas representan nuevos lugares, zonas digitales donde un gran número de individuos se encuentran. En estas, las personas construyen comunidades mediante el intercambio de sus vivencias. Así, los grupos humanos que allí conviven manifiestan sus inquietudes a través de discursos escritos, orales y gráficos.

El desarrollo de secuencias didácticas que favorezcan la escritura creativa en las redes sociales es muy posible. Solo se necesita la orientación de los profesores para que los estudiantes realicen eficazmente actividades formativas en estos espacios. De hecho, redes sociales, como Instagram, son idóneas para desarrollar competencias lingüísticas como la redacción de microrrelatos y para favorecer el aprendizaje colaborativo. En tal sentido, Medina Oviedo (2019) plantea que muchos alumnos no logran las competencias de lectura y escritura mediante los modelos educativos tradicionales, pero al incluir las TIC, en la realización de actividades de lectura y escritura, obtienen mejores resultados.

Según lo planteado en la introducción, el proceso de alfabetización académica es responsabilidad de todos los docentes sin importar si son o no del área de Lengua y Literatura. Por lo tanto, los profesores de otras asignaturas pueden utilizar esta propuesta o alguna parecida, porque el desarrollo de las competencias lingüísticas no debe ser una tarea exclusiva del profesor de lengua; y, además, la internet y las redes sociales pueden y deben ser asumidas como recursos didácticos.

En tal sentido, Castillo y Cabrerizo (2006) consideran que la elección de un recurso didáctico depende de cinco criterios esenciales, a saber: los objetivos, los contenidos, los estudiantes, el contexto y las estrategias didácticas. Partiendo de estos, si se diseña correctamente la secuencia didáctica, Instagram puede funcionar como recurso de enseñanza-aprendizaje porque permite lograr el objetivo de la producción de textos breves creativos; porque los estudiantes disfrutan y se sienten motivados en sus entornos habituales, por tanto, se incluye el componente emocional tan importante para el aprendizaje (Elizondo, Rodríguez y Rodríguez, 2018) y porque, por su versatilidad, ofrece a los docentes ideas innovadoras para estrategias de aprendizaje.

Definitivamente, las nuevas tecnologías son parte importante de la sociedad. Por lo tanto, deben integrarse en los procesos formativos de manera consciente y con objetivos establecidos por el maestro. Los jóvenes de hoy necesitan y requieren cambios fundamentales en las prácticas que se desarrollan dentro y fuera de las aulas. Por eso, esta propuesta didáctica representa una oportunidad para los docentes, especialmente, los del área de Lengua y Literatura.

\section{Referencias}

Árdenas Ruiz, J. A. (2018). Una reflexión de la vivencia de un maestro, desde el concepto de resignificación, a partir de la apropiación del 
microrrelato como técnica de investigación. Revista Aletheia, 10(1), 44-57. Pintura: Carolina Latorre@

Blanco Sánchez, M. I. (2012). Recursos didácticos para fortalecer la enseñanza-aprendizaje de la economía. Aplicación a la Unidad de Trabajo "Participación de los trabajadores en la empresa" (tesis de maestría). Universidad de Valladolid, Valladolid, España.

Blasco-Serrano, A. C., Lorenzo Lacruz, J., y Sarsa, J. (2018). Percepción de los estudiantes al 'invertir la clase' mediante el uso de redes sociales y sistemas de respuesta inmediata. Revista De Educación a Distancia, 18(57). Recuperado a partir de https://revistas.um.es/ red/article/view/327391

Calle Álvarez, G. Y. (2018). La escritura académica apoyada por un Centro de Escritura Digital en la educación media. Lenguaje, 46(2), 334361. https://dx.doi.org/10.25100/lenguaje. v46i2.6586

Canales Gabriel, R. (2014). Lenguaje oral y habilidades prelectoras en niños de 4 a 6 años. Un estudio sobre marginalidad y bilingüismo en el Perú. Revista De Investigación En Psicología, 17(1), 107-119. https://doi.org/10.15381/ rinvp.v17i1.8974

Cancino Peña, J., Fontecha Barbosa, S., Ramírez Amado, N., y Parra Arias, E. (2019). La escritura creativa: de las fronteras del conocimiento científico a los límites de la imaginación. Publicuidad: Revista Latinoamericana de Publicidad, 8(1), 91 - 105. doi: http://dx.doi. org/10.18566/publicuidad.v08n01.a06Alonso

Carlino, P. (2005). Escribir, leer y aprender en la universidad. Una introducción a la alfabetización académica. Buenos Aires: Fondo de Cultura Económica.

Castillo Arredondo, S. y Cabrerizo Diago, J. (2006). Formación del profesorado en educación superior. Didáctica y Curriculum. Volumen I. Madrid: McGraw Hill

Cantón Correa, D. F. J. C., y Pascual, J. A. (2018). Visualizando ciudades a través de Instagram: la construcción de la cultura visual urbana. In Investigación multimedia: el análisis de contenido en la era digital (pp. 231-254). Egregius.

Draus Kłobucka, A. (2019). Microrrelato, bitácora y la preocupación social. Microtextualidades. Revista Internacional de microrrelato $y$ minificción, O(5), 67-76. Recuperado de http://revistas.uspceu.com/index.php/ microtextualidades/article/view/147/113

Elizondo, A., Rodríguez, J. y Rodríguez, I. (2018). La importancia de la emoción en el aprendizaje: Propuestas para mejorar la motivación de los estudiantes. Cuaderno de Pedagogía Universitaria. Vol. 15, no. 29, enero-junio 2018. doi: https://doi.org/10.29197/cpu.v15i29.296

Fernández, A. (2019). El microrrelato: una poética de la intertextualidad / Microfiction: a poetics of intertextuality. Microtextualidades. Revista Internacional de microrrelato y minificción, 0(5), 93-105. Recuperado de http://revistas. uspceu.com/index.php/microtextualidades/ article/view/150/115

García, M. y Álvarez, G. (2009). La reformulación de texto fuenteen alumnos de nivel preuniversitario: una propuesta superadora de las dificultades en la producción del texto escrito. Proceedings of Jornadas de Enseñanza de la Lengua y la Literatura. Leer y escribir: nuevas miradas sobre viejas prácticas. Los Polvorines: Universidad Nacional de General Sarmiento.

García, M. y Álvarez, G. (2010). Hacia una propuesta superadora de las dificultades de alumnos preuniversitarios en reformulaciones productivas del texto fuente. Onomazein, 21 (1): 191-223.

Hernández, D. (2016). El estudio del microrrelato. La revitalización de la filología. Forma: revista d'estudis comparatius. Art, literatura, pensament, (13), 67-76.

Jurado, S. B., Woelfert, E., Giovagnola, A. C., Faisal, F. B., y Peralta, R. V. (2018). La incorporación de la red social Instagram con fines didácticos en el Curso de Microscopía Electrónica de la FCV-UNLP. En I Jornadas de Inclusión 
de Tecnologías Digitales en la Educación Veterinaria (La Plata, 2018). Recuperado de http://sedici.unlp.edu.ar/handle/10915/71727

Larrea, M. (2004). Estrategias lectoras en el microcuento. Estudios filológicos, (39), 179190. https://dx.doi.org/10.4067/S007117132004003900011

Larrea, M. (2019). El microcuento en Hispanoamérica. Revista Documentos Lingüísticos y Literarios UACh, 0 (37), 161-168. Recuperado de http://revistadll.cl/index.php/ revistadll/article/view/403/703

Liu, X. (2019). Tuitescritura y Tuiteratura en China: Microrrelato en Weibo / Tweet Writing and Tweet Literature in China: Short Short Story in Weibo. Microtextualidades. Revista Internacional de microrrelato y minificción, O(5), 153-162. Recuperado de http://revistas. uspceu.com/index.php/microtextualidades/ article/view/209/122

Marín Díaz, V. y Cabero Almenara, J. (2019). Las redes sociales en educación: desde la innovación a la investigación educativa. RIED. Revista Iboeroamericana de Educación a Distancia, 22 (2), 25-33.

Martínez Carranza de Delucchi, S. (2011). Un microrrelato de Borges desde adentro. Cuadernos del CILHA, 12(2), 61-69. Recuperado en 09 de octubre de 2019. Recuperado de http://www.scielo.org.ar/ scielo. php?script=sci_arttext\&pid=S185296152011000200007\&lng=es\&tlng=es.

Medina Oviedo, E. (2019). Lectura y escritura mediante investigación como estrategia pedagógica apoyada en TIC. Cultura educación y sociedad, 9(3), 893 - 904. https:// doi.org/10.17981/cultedusoc.9.3.2018.106

Mendieta Sierra, K. (2018). La escritura creativa como herramienta para el desarrollo de la competencia literaria. (Tesis de grado). UNIVERSIDAD PEDAGÓGICA NACIONAL, Bogotá, Colombia.

Olave Arias, G., Cisneros Estupiñán, M. y Rojas García, I. (2013). Deserción universitaria y alfabetización académica. Educación y Educadores, 16(3). Recuperado de https://www. redalyc. org/articulo.oa?id=834/83429830004

Páez, E. (2007). Escribir: manual de técnicas narrativas. Madrid, España: Ediciones SM.

Pérez Sánchez, M. y Pérez Morán, L. (2019). Formas de enseñanza y materiales educativos: de lo tradicional a lo actual. Revista Educinade. 2 (3), 5-10. Recuperado de https://www.cinade.edu.mx/img/revista/ Revista_Educinade_No.3.pdf\#page $=5$

Piacente, T. y Tittarelli, A. M. (2006). Comprensión y producción de textos en alumnos universitarios: la reformulación textual. Orientación y Sociedad, Vol. 6, 99-126.

Romero Valdés, H., Ojeda Ramírez, M., y Díaz González, M. (2018). Formación de lectores en bachillerato mediante la lectura recreativa de textos narrativos tradicionales. Álabe, 0 (19). doi: http://dx.doi.org/10.15645/ Alabe2019.19.3

Sierras Gómez, M. (2002). Diseño de medios y recursos didácticos. España: Innovación y calificación, S. L.

Unesco (2008). El Desafío de la alfabetización en el mundo: perfil de alfabetización de jóvenes y adultos a mitad del Decenio de las Naciones Unidas de la Alfabetización 2003-2012. Paris. 


\section{Rúbrica de evaluación de microrrelato}

Maestro/a:
Estudiante:

\begin{tabular}{|c|c|c|c|c|}
\hline Categorías & 4 & 3 & 2 & 1 \\
\hline $\begin{array}{l}\text { Ortografía y } \\
\text { puntuación }\end{array}$ & $\begin{array}{l}\text { No hay errores de ortografía o } \\
\text { puntuación en el borrador final. }\end{array}$ & $\begin{array}{l}\text { Hay un error de ortografía } \\
\text { o puntuación en el } \\
\text { borrador final. }\end{array}$ & $\begin{array}{l}\text { Hay de 2-3 errores de } \\
\text { ortografía y puntuación en } \\
\text { el borrador final. }\end{array}$ & $\begin{array}{l}\text { El borrador final tiene } \\
\text { más de } 3 \text { errores de } \\
\text { ortografía y puntuación. }\end{array}$ \\
\hline Acción & $\begin{array}{l}\text { Varios verbos de acción (voz } \\
\text { activa) son usados para describir } \\
\text { lo que está pasando en el } \\
\text { cuento. jEl cuento parece ser } \\
\text { emocionante! }\end{array}$ & $\begin{array}{l}\text { Varios verbos de acción } \\
\text { son usados para describir } \\
\text { lo que está pasando en el } \\
\text { cuento, pero la elección } \\
\text { de palabras no hace al } \\
\text { cuento tan emocionante. }\end{array}$ & $\begin{array}{l}\text { Una variedad de verbos } \\
\text { (voz pasiva) son usados } \\
\text { y describen la acción } \\
\text { de forma precisa pero } \\
\text { no de manera muy } \\
\text { emocionante. }\end{array}$ & $\begin{array}{l}\text { Poca variedad vista } \\
\text { en los verbos usados. } \\
\text { El cuento parece ser } \\
\text { aburrido. }\end{array}$ \\
\hline $\begin{array}{l}\text { Proceso de } \\
\text { escritura }\end{array}$ & $\begin{array}{l}\text { El estudiante dedica mucho } \\
\text { tiempo y esfuerzo al proceso de } \\
\text { escritura (preescritura, borrador } \\
\text { y edición). Trabaja duro para } \\
\text { crear una historia interesante. }\end{array}$ & $\begin{array}{l}\text { El estudiante dedica } \\
\text { tiempo y esfuerzo } \\
\text { suficiente al proceso de } \\
\text { escritura (preescritura, } \\
\text { borrador y edición). } \\
\text { Trabaja y termina el } \\
\text { trabajo. }\end{array}$ & $\begin{array}{l}\text { El estudiante dedica algo } \\
\text { de tiempo y esfuerzo al } \\
\text { proceso de escritura, pero } \\
\text { no fue muy cuidadoso. Su } \\
\text { trabajo es mediocre. }\end{array}$ & $\begin{array}{l}\text { El estudiante dedica } \\
\text { poco tiempo y esfuerzo al } \\
\text { proceso de escritura. No } \\
\text { le parece importar. }\end{array}$ \\
\hline $\begin{array}{l}\text { Enfoque en el } \\
\text { tema asignado }\end{array}$ & $\begin{array}{l}\text { El cuento está completamente } \\
\text { relacionado al tema asignado } \\
\text { y permite al lector entenderlo } \\
\text { mejor. }\end{array}$ & $\begin{array}{l}\text { La mayor parte del } \\
\text { cuento está relacionado } \\
\text { al tema asignado. } \\
\text { El cuento divaga en } \\
\text { un punto, pero el } \\
\text { lector todavía puede } \\
\text { comprender algo del } \\
\text { tema. }\end{array}$ & $\begin{array}{l}\text { Algo del cuento está } \\
\text { relacionado al tema } \\
\text { asignado, pero el lector } \\
\text { no puede comprender } \\
\text { mucho del tema. }\end{array}$ & $\begin{array}{l}\text { No hay ningún intento de } \\
\text { relacionar el cuento al } \\
\text { tema asignado. }\end{array}$ \\
\hline $\begin{array}{l}\text { Precisión de } \\
\text { los hechos }\end{array}$ & $\begin{array}{l}\text { Todos los hechos presentados en } \\
\text { el cuento son precisos. }\end{array}$ & $\begin{array}{l}\text { Casi todos los hechos } \\
\text { presentados en el cuento } \\
\text { son precisos. }\end{array}$ & $\begin{array}{l}\text { La mayoría de los hechos } \\
\text { presentados en el cuento } \\
\text { son precisos (por lo } \\
\text { menos } 75 \% \text { ). }\end{array}$ & $\begin{array}{l}\text { En el cuento hay varios } \\
\text { errores basados en los } \\
\text { hechos. }\end{array}$ \\
\hline Creatividad & $\begin{array}{l}\text { El cuento contiene muchos } \\
\text { detalles creativos y/o } \\
\text { descripciones que contribuyen } \\
\text { al disfrute del lector. El autor } \\
\text { realmente usó su imaginación. }\end{array}$ & $\begin{array}{l}\text { El cuento contiene } \\
\text { algunos detalles creativos } \\
\text { y/o descripciones que } \\
\text { contribuyen al disfrute } \\
\text { del lector. El autor usó su } \\
\text { imaginación. }\end{array}$ & $\begin{array}{l}\text { El cuento contiene pocos } \\
\text { detalles creativos y/o } \\
\text { descripciones, y estos } \\
\text { distraen la trama. El autor } \\
\text { ha tratado de usar su } \\
\text { imaginación. }\end{array}$ & $\begin{array}{l}\text { Hay poca evidencia de } \\
\text { creatividad en el cuento. } \\
\text { El autor no parece haber } \\
\text { usado su imaginación. }\end{array}$ \\
\hline Requisitos & $\begin{array}{l}\text { Todos los requisitos solicitados } \\
\text { (cantidad de palabras, se ajusta } \\
\text { a las dos opciones establecidas } \\
\text { en el ejercicio, etc.) fueron } \\
\text { cumplidos. }\end{array}$ & $\begin{array}{l}\text { Casi todos (sobre 90\%) } \\
\text { de los requisitos fueron } \\
\text { cumplidos. }\end{array}$ & $\begin{array}{l}\text { Casi todos (sobre } 75 \% \text { ) } \\
\text { de los requisitos fueron } \\
\text { cumplidos, pero algunos } \\
\text { de los importantes no se } \\
\text { cumplieron. }\end{array}$ & $\begin{array}{l}\text { Muchos requisitos no } \\
\text { fueron cumplidos. }\end{array}$ \\
\hline
\end{tabular}

